Ethiopian Journal of Environmental Studies \& Management 8(Suppl. 1): 846 - 854, 2015.

ISSN:1998-0507

doi: http://dx.doi.org/10.4314/ejesm.v8i1.12S

Submitted: July 05, 2015

Accepted: October 23, 2015

\title{
GEOGRAPHICAL ANALYSIS OF ROAD TRANSPORTATION OF ETHIOPIA
}

\section{MUSHIR ALI AND HAILEMARIAM MEAZA}

Department of Geography and Environmental Studies, Mekelle University, PB.451 Mekelle, Ethiopia

\begin{abstract}
Roads are considered efficient in transportation system to provide quick, short and medium distance services for the socio-economic development of the country. They are life line for the remote areas where supply and exchange of goods and services are performed by roads. The distribution of roads is not homogenous and orderly fashion to stimulate sectors of economy of developing countries. The present study was conducted in Ethiopia keeping consideration of the objectives to assess growth and distribution of roads by area, population, and to explain causes for regional variations of road development. Secondary data were used for geographical analysis of Ethiopian roads distribution and inter-regional variations between 1992 and 2009. The analysis of the data reflects that growth of constructed roads was 9.86\% per year and it was 34.69\% during 1993-1994. There was high share of well connected kebeles (73-92\%) by community roads in Tigray and Afar regional states. However, availability of roads per $1000 \mathrm{~km}^{2}$ was higher $96.2 \mathrm{~km}$ in Southern Nations Nationalities People Region and Dare Dawa. The length of kebele roads by inhabited area and by high accessibility within $2 \mathrm{~km}$ from the roads was in southern and western states.
\end{abstract}

Key Words: Roads, Distribution, Accessibility, Connectivity index, Regional States

\section{Introduction}

Road transportation has played a dynamic role in developing economy, commercial life and trade, traditions, and generally shaped the thought, the culture and the socio-economic life of people of sub-Saharan countries particularly in Ethiopia, where other means of transportation is not easily available (Carruthers, et al., 2008; Gwilliam, et al., 2008). Road transport facilitates exchange of agro-produces, industrial products, services from the surplus regions to deficit and remote areas and has contributed to national development in Ethiopia since last centuries (Tunde and Adeniyi 2012; Temesgen 2007). Agriculture as the main source of revenue accounts for $46.5 \%$ of the GDP and $83.9 \%$ of exports and $85 \%$ of total employment, is directly and indirectly reliant on roads (Bekele, 2007; ERA 2011). Roads lead to transport more than $93 \%$ of freight and $95 \%$ of all passengers of Ethiopia and considered well functioned economic activity to ensure development particularly for tourism and social cohesion of population in Ethiopia (ERA, 2010; Mushir and Neka, 2012; Ajala, 2008).

Therefore, road transportation has continued to be central to all strategies plans for development of rural and urban areas of the country. It is road transport that ensures everyday mobility of people, and is essential to achieve self-reliance, household level food security, to reach 
poverty alleviation schemes at grass roots level (Limao and Anthony, 2001). A well knitted road transport is considered an indicator of socio-economic development that play crucial role in availability, accessibility and distribution of goods, income, wealth and services in Ethiopia where the relief ranges $126 \mathrm{~m}$ from mean below sea level to $4630 \mathrm{~m}$ (Abate 2013;Temesgen 2007). Total Ethiopian stock road network was $6400 \mathrm{~km}$ in 1951 and reached $48793 \mathrm{~km}$ in 2010 (ERA, 2011).

Roads are clearly related to critical enabling conditions for improving living in different rural parts of the country. However, the distribution of socioeconomic benefits resulting from a rural road is considered an inherent mechanism to ensure the benefits may be distributed equitably between the poor and the nonpoor in communities (Mushir, 2013; Buys et al., 2010; Bekele, 2007). Regional patterns of agricultural production and rural income variations have similarly been positively associated with transport infrastructure in Ethiopia (Abraham, 1982). The bad conditions of the road affect distribution of goods as well as cost of transportation of agro-products which affect the rural farmers' income and their work participation among rural masses. Keeping in view the importance of the road distribution and development, the study was conducted with the following objectives;

To assess growth and the regional distribution of roads by area, population,
To explain causes to regional variation of road distribution

\section{Study Area}

Ethiopia is land locked country, located in the Horn of Africa. It is bordered by Eritrea to the north, Djibouti and Somalia to the east, Sudan and South Sudan to the west, and Kenya to the south. It lies within the tropics $3^{\circ} 24^{\prime}$ and $14^{\circ} 53^{\prime} \mathrm{N}$ latitudes and $32^{\circ} 42^{\prime}$ and $48^{\circ} 12^{\prime} \mathrm{E}$ longitudes. It covers 1.12 million sq $\mathrm{km}$ where $86,613,986$ persons live in nine regional states whereas $82.46 \%$ population resides in rural spaces. It has the highest mountain (Ras Dashen-4630 m) as well as the lowest point-Lake Asal (126 m below sea level), Somali and Afari deserts. Elevation is generally the higher just before the point of descent to the Great Rift Valley, which splits the plateau diagonally. The height of central plateau of Ethiopia varies from 1,290 to $3,000 \mathrm{~m}$ above sea level. A number of rivers and streams, like the Blue Nile, the Takeze and the Awash and their tributaries cross the plateaus. Many of the rivers cut deep gorges and sharp valleys and slopes. The plateau gradually slopes to the lowlands of the Sudan on the west and the Somali-inhabited plains to the east. The topography and drainage of different rivers affect the distribution of roads in all regional states. Diverse rainfall and temperature patterns prevail in various regions on the basis of altitude. Temperature and rainfall vary between $12^{\circ} \mathrm{C}$ to $40^{\circ} \mathrm{C}$ and $60 \mathrm{~mm}$ to $600 \mathrm{~mm}$ respectively (Abate, 2013; TGE, 1992). 


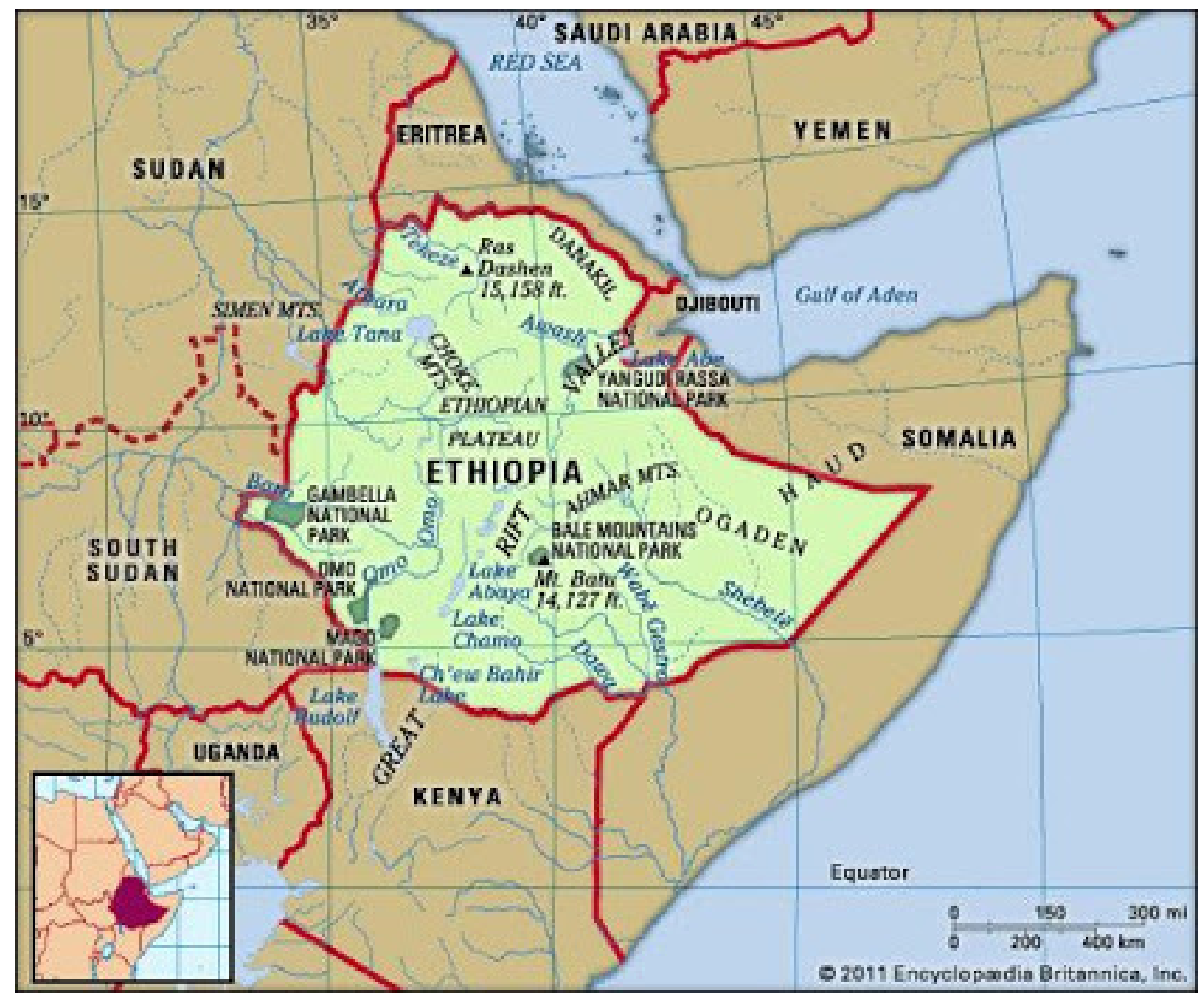

Source: Encyclopedia Britannica (2011)

Location map of Study Area

\section{Methodology}

The entire work is based on secondary sources of data gathered from Ethiopian Roads Authority (ERA), Ministry of Transport, published materials of Road Transport and Development Performance (RSDP). Obtained information was analyzed on the basis of descriptive research method using simple statistical technique. Moreover, range method was used for level of growth and distribution of roads regarding land, area, population, types and census status of road development amongnine regional states of Ethiopia.The data were also analyzed and represented with the help of choropleth maps and line diagrams. The following formula is used to show the distribution (high, medium and low) of different aspects of road transportation (Mushir et al., 2007).

$$
L R D=\frac{H l r-L l r}{c i}
$$

Where,

$L R D=$ Level of Road Development

$H l r=$ Highest value of road length

$L l r=$ Lowest value of road length

$C i=$ number of significance classes

\section{Results and Discussions}

The road infrastructure is the main form of infrastructure serving more than $95 \%$ of the volume of tons $\mathrm{km}$ and passenger $\mathrm{km}$ in the country (Ibrahim, 2011). The extent, to which different parts of the country are served by the road network, is an indication of the 
connectivity. However, in different parts of the country, political instability and induced non-practical administration were serious challenges to the road development. Such challenges had been effectively managed after July 1991 by the
Transitional Government of Ethiopia. There were roads constructed rapidly, particularly rural gravel (Figures 1and 2) to make accessibility regarding security, administration and good governance purposes (Ibrahim, 2011; ERA, 2010).

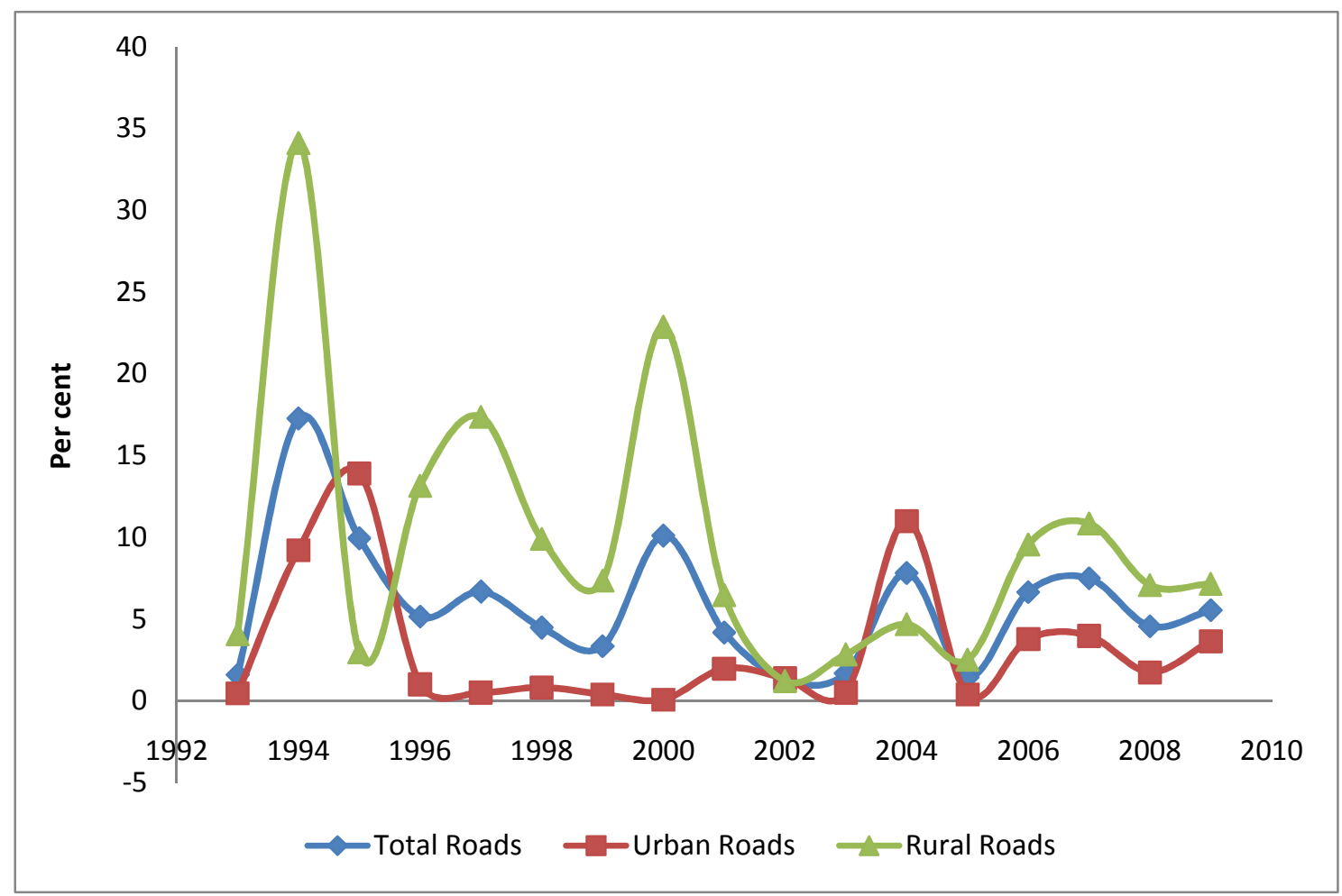

Source: Ethiopian Road Authority (2011)

Figure 1: Growth of Rural and urban Roads in Ethiopia, 1992-2009

\section{Growth and Distribution of Roads}

Government had given priority to construction of rural roads. The development of roads was on an average of 9.86\% per year between 1992 and 2009 but it was higher (34.69\%) during 1993-94 (Fig. 1) it was an effort of newly formed transnational government which paid more attention to connect rural areas. The growth of urban roads was $3.22 \%$ between 1992 and 2009 (Fig 2). It was the highest $13.9 \%$ during $1994-95$ and $11 \%$ in $2004-$ 05. The increase in road construction coincided with the period before general elections or during the year of elections which is a common trend in developing countries. 


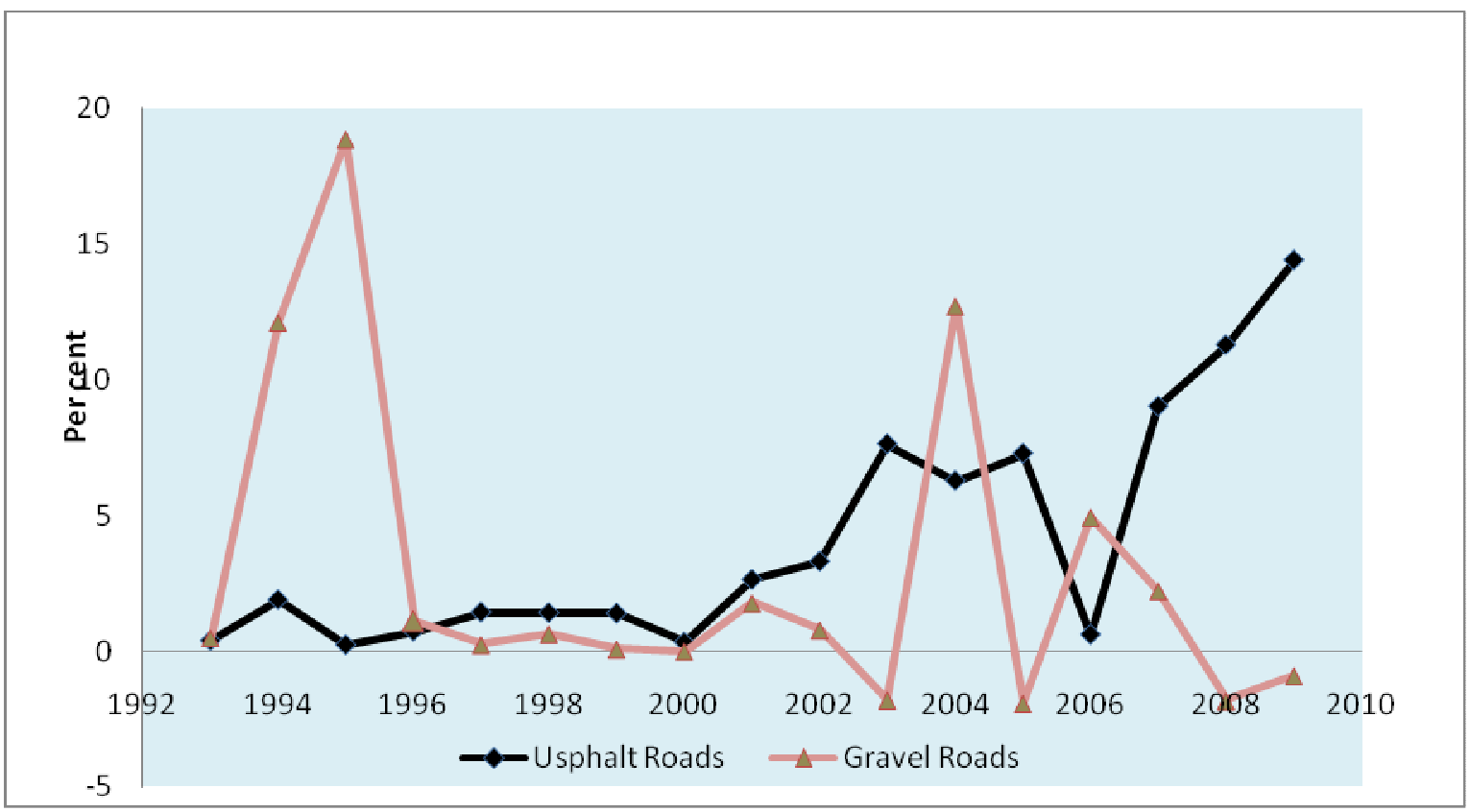

Source: Ethiopian Road Authority, 2011

Figure 3: Growth of Gravel and Asphalt Roads in Ethiopia, 1992-2009

Nearly $80 \%$ of the population depends on the use of traditional modes of transport that is head and back loading, walking and animal transport which are slow, burdensome and time consuming (ERA, 2011). Undulating topography, sharp slope, erratic nature of rainfall, lot of hilly streams those are challenge to construct all weather roads. However, most of all weather roads in the national network were concentrated in the central, eastern, and northern highlands. All weather roads were developed at higher level in Tigray region of Ethiopia; there were a large number of kebeles connected with all-weather roads (Figure 3). Tigray has been strategic region since silk route was developed to connect all known world. The Italian's invaded and development of Asmara-Addis Ababa, later wars between Ethiopia and Eritrea, at contributed a lot to connect all weather roads. It is also believed that after formation of the Tigray Peoples Liberation Front (TPLF) government since 1993, the attention was paid more to connect kebeles. However, by length of roads, majority of kebeles, (2575) of Oromya region were connected.

Rural communities become often isolated and left without access, particularly during periods of rains due to remoteness, isolation scattered settlements. There was lack of investment in road transport affect the improvement for the wellbeing of the poor: access to social services and facilities, access to market, access for employment opportunities; and reduces the negative impacts of natural disasters and shocks and provides the links needed to manage it (ERA, 2009, 2010).

More than 100 woredas have a ten-year strategic plan and annual development plan that includes road provision and maintenance. Better local planning is having an impact on the quality of local transport and services. Sensible planning of other essential infrastructure, such as clinics, schools and water supplies, can, when provided with reliable linkages, bring facilities ever closer to the rural poor (MoTERA, 2011).There are new rural road construction, upgrading (improving the 
existing) and rehabilitation (restoring an existing road to its originally constructed or subsequently upgraded). Road maintenance is larger expense and difficult service in road management. However, the rural roads and transport development program has systematically been prepared to meet the infrastructure and transport service requirements for mobility and accessibility in relation to socio-economic realities, and anticipated opportunities and constraints.

The lesser development of road infrastructure was recorded in Southern part of the country. High humidity, rainfall and sparse population in the southern nations are major influencing factors to lower development of rural roads (ERA, 2010). The northern part of country is comparatively well connected with roads (Figures 3 and 4). Whereas since ancient time, the northern part of the country was routed to get entry for trade of gold, animal, and timber products in the internal part of Africa (World Bank, 2007; Hoyle and Jacques, 1995; Gwilliam, 2011; Eleanor, 2014; Atta, 2015).

After Eretria and Ethiopia war (1993), the attention has been to develop asphalt roads transport during 1993-2008 (Mushir and Hawet, 2012). However due to physiological, economic and technical constraints, the investment to develop road the growth was lower. More than two decades political stability has attracted investment for development of roads on north central Ethiopia. Moreover, roads have been construction rapidly because government wants to boost tourism destinations in the north-central parts of the country (Ajala, 2008).

The overall growth of the roads is high, it was realized just after Eritrean war and emphasis was given to connect every corner of the country. As a result, all weather and dry roads were developed throughout the country as community roads particularly in rural areas. Roads have also been recognized for development as they play the important role to disseminate the agricultural input for production rural sphere and output for urban consumer sphere. Such a way growth of the roads construction was recorded high (Figure 2) in all regional states. But there were kebeles not equally connected (Figure 4) due to economic, physical, and political constraints even after passing twenty years as stable and economic growing Ethiopian economy. There was high share (73-92\%) of kebeles those were connected by community (dry and all weather) roads in Tigray and Afar regional states, followed by Southern Nations Nationalities People Region, Amhara and Dire Dawa states belonging to medium categories, where $54-73 \%$ kebeles were connected by community roads (Figure 5). The low level of connectivity (35-54\%) by community roads was found in Somali, Benshangul Gumuz, Gambella and Oromya states respectively.

There was availability of roads on per $1000 \mathrm{sq}$ area was high $96.2 \mathrm{~km}$ in Southern Nations Nationalities People Region and Dare Dawa (Figure 6). The majority of states, i.e, Tigary Amhara, Oromya, Beshangul Gumuz and Gambela belonged to medium categories Tigray where the roads were developed 42.9 to $69.6 \mathrm{~km}$ on $1000 \mathrm{~km}^{2}$. Afar and Somali were in the bottom category in this regard because of desert nature and small distribution of habited areas. Besides, due to comparatively more area than population, desert and semi desert type of climate, backward in agriculture, industrial and service sectors, the construction of roads is lowest in comparison of other states. 


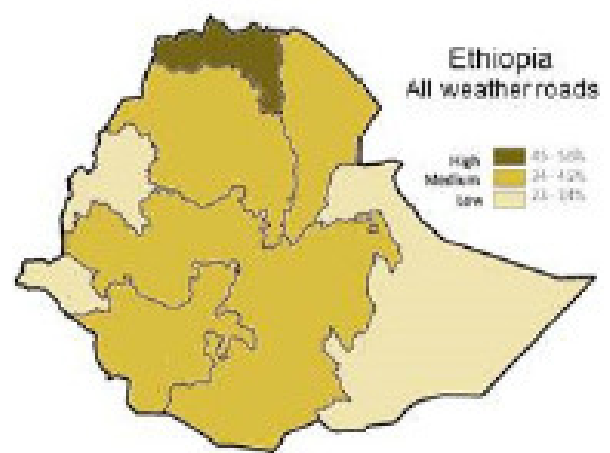

Fig. 3

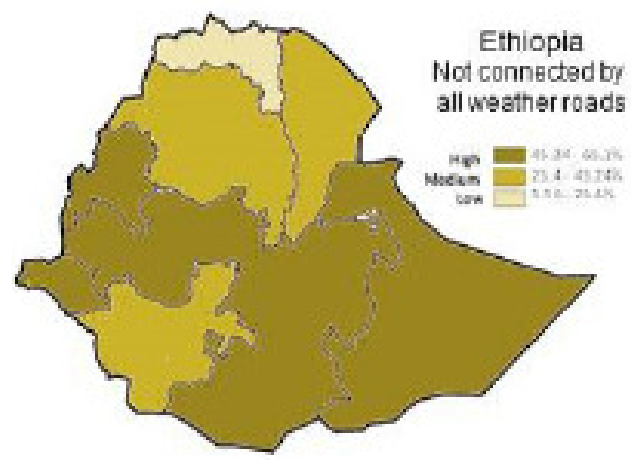

Fig. 5

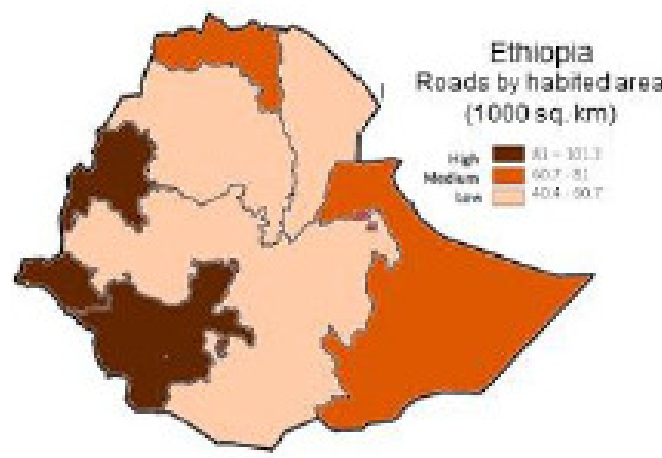

Fig. 7

Ethiopia has nearly 94 million populations with density 82 persons $/ \mathrm{km}^{2}$. The states belonged high length of road $(81-101.2 \mathrm{~km})$ on $1000 \mathrm{sq} \mathrm{km}$ inhabited area was recorded as Southern Nations Nationalities People region, Beshangul Gumuz, Dare Dawa and Gambella. Medium range of road length (60.6$81 \mathrm{~km} / 1000 \mathrm{~km}^{2}$ ) was in Tigray and Somali

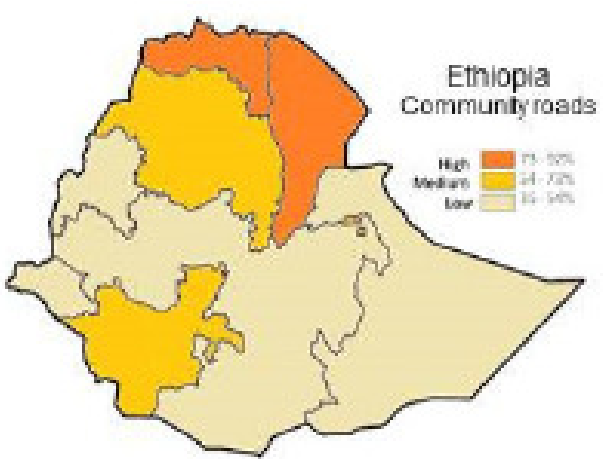

Fig. 4

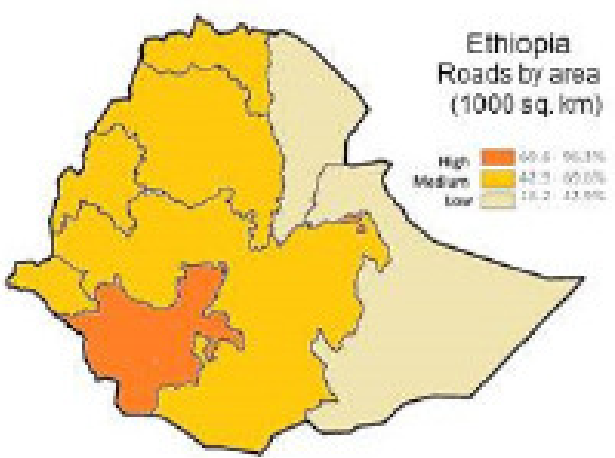

Fig. 6

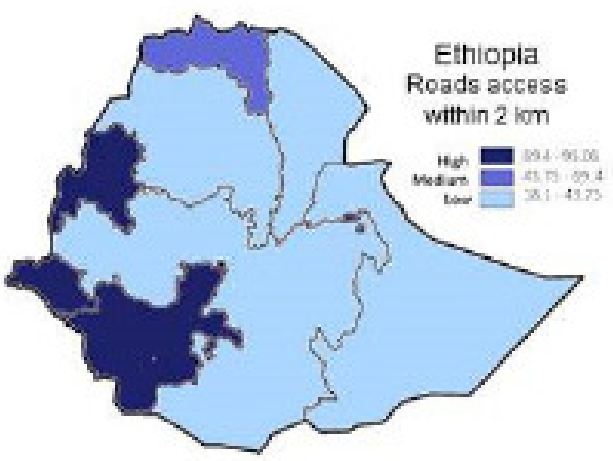

Fig. 8 regions. While low level length of road distribution inhabited area wise was recorded in Afar, Amhara and Oromya (Figure7).

It was noted through the interpretation Figure 8 the high accessible kebeles were in Southern Nations Nationalities People region, Beshangul Gumuz, Dare Dawa and Gambella, whereas 69.4-95.06\% kebeles 
had the accessibility within $2 \mathrm{~km}$ from the roads. Tigray belonged to medium categories where the access within $2 \mathrm{~km}$ was 43.75-69.4\%. However, low accessibility was recorded in Amhara, Oromoya, Afar and Somali regions respectively.

\section{Conclusion}

The Ethiopian road system trails a star pattern in which Addis Ababa is situated at the centre, from where both asphalt and gravel roads are radiated to different directions to make accessibility for hubs of urban and rural population, commercial, industrial and agricultural activities. At parts of different of the country, growth and development roads is not homogenous due to physical, political social and economic constraints. There were west, southwest and southeast parts still lacks of all-weather roads connectivity. Most roads network was concentrated in the central, eastern, and northern highlands. About $12 \%$ of the population only $20 \%$ of Ethiopian entire land area has access to roads within a $10 \mathrm{~km}$ range of an all-weather road, and the walking time to a motorable road currently averages more than six hours for over $50 \%$ of the population. Moreover, policy makers have been working to reduce the average to less than three hours.

At least all the sectors (agriculture, industrial, services) of Ethiopian economy are growing positively so they require road transportation. However, transport has been grown a level but to reach world class level there a need intensive policy for the balance development of roads in every region of Ethiopia. Ethiopia requires the further programmes to construction of roads at regional, woreda, kebele level to achieve inclusive growth and regional balance in Ethiopia.

\section{References}

Abate, S.D. (2013). Land use Challenges in the Legemara Watershed, North Central Highlands of Ethiopia." Ethiopian Geographical Journal, 6(1): 36-61.

Abraham, G. (1982). "The Impact of Roads on Regional Development".In Proceedings of the 7 th International Conference of Ethiopian Studies. Lund.

Ajala, O.A. (2008). "Employment and Income Potentiality of Tourism Development in Amhara Region". Ethiopian Journal of Environmental Studies \& Management, 1(2): 74-82.

Atta, T. (2015) 'Places to Visit from Cairo to Cape Town Highway". http://www.atta.travel/news/4582/10places-to-visit-from-cairo-to-capetown (accessed 23/04/2015)

Bekele, N. (2007). "Road and Development in Ethiopia" Economic Focus, 9(4): 30-45

Buys, P., Uwe, D. and David, W. (2010) "Road network upgrading and overland trade expansion in subSaharan Africa," Journal of African Economies, 19(3): 399-432.

Carruthers, R., Krishnamani, R.R. and Murray, S. (2008). "Investing in Transport, Infrastructure in SubSaharan Africa, Africa Infrastructure Country Diagnostic". Summary to Background Paper 7 International Bank for Reconstruction and Development/The World Bank Washington, DC

Eleanor, W. (2014). "The Trans-African Highway, a road network linking Africa's major cities, is far from complete, 43 years on' Good Governance Africa." http://gga.org/stories/editions/aif-22apart-at-the-seams/road-to-nowhere (accessed 25/01/2015) 
ERA (2009). "The Road Sector Development Programme: RSDP Performance Twelve years later". The Federal Democratic Republic of Ethiopia, Ministry of Works \& Urban Development, Ethiopian Roads Authority, Addis Ababa

ERA (2010). "Revised Universal Rural Road Access Program".Ethiopian Road Authority Addis Ababa.

ERA (2011). "The Road Sector Development Programme: RSDP Performance Thirteen years later". The Federal Democratic Republic of Ethiopia, Ethiopian Roads Authority, Addis Ababa

Gwilliam, K.M. (2011). Africa's Transport Infrastructure". World Bank, Washington, DC:

Gwilliam, K.M., Foster, V., Archondo, C.R., Briceno, G.C., Nogales, A. and Sethi, K. (2008) "The Burden of Maintenance: Roads in Sub-Saharan Africa Improving Connectivity". Africa Infrastructure Country Diagnostic, Summary to Background Paper 14 International Bank for Reconstruction and Development / The World Bank Washington, DC

Hoyle, B. and Jacques, C. (1995) "Interport competition in developing countries: an East African case study," Journal of Transport Geography, 3(2):87-103.

Ibrahim, W. (2011). "Road Sector Development and Economic Growth in Ethiopia”. EDRI Working Paper 4, Ethiopian Development Research Institute, Addis Ababa, Ethiopia: 412.

Limao, N. and Anthony V. (2001). "Infrastructure, Geographical Disadvantage, Transport Costs and Trade". The World Bank Economic Review, 15(3): 451-479.
MoTERA (2011). "Woreda Rural Road Development Program (URRDP)". Ministry of Transport Ethiopian Road Authority Addis Ababa.

Mushir, A., Khan, M.M. and Khan, N. (2007). "Hierarchy of Periodic Market Centres in Shahjahanpur District”. Indian National Geographer, 22(1\&2): 185-195.

Mushir, A.and Hawet, K. (2012). "Socioeconomic Conditions of Female Headed Households in Conflict Zone: A Case Study of Ethiopia". Asia-Pacific Journal of Social Science, 4(2): 171-186.

Mushir, A. (2013). "Socio-Economic Status of Tigrean Ethnic Immigrants, the Case of North Ethiopia". Journal of Settlements and Spatial Planning, 4(2): 239-247.

Mushir, A. and Neka, M. (2012). "Livestock Husbandry and Economic-Sustainability of Small Farmers in Peri-Urban Areas: A Case Study from West Gojjam Region, Ethiopia”. Ethiopian Journal of Environmental Studies and Management, 5(2): 207-217.

Temesgen, A. (2007). "The Role of the Transport Sector in Ethiopia's Economic Development". Economic Focus, vol. 9 (4): 17-29.

TGE (1992). Ethiopia National Report on Environment and Development, Addis Ababa.

Tunde, A.M. and Adeniyi, E.E. (2012). "Impact of Road Transport on Agricultural Development: A Nigerian Example". Ethiopian Journal of Environmental Studies and Management, 5(3): 232-238

World Bank (2007). "Decade of Action in Transport: An Evaluation of World Bank Assistance to the Transport Sector, 1995-2005". World Bank, Washington, DC. 